\title{
Quantitative evaluation of the effectiveness of best available technologies of form-shaping
}

\author{
Leonid Shvartsburg ${ }^{1, *}$, Elena Butrimova ${ }^{1}$, and Olga Yagolnitser $^{1}$ \\ ${ }^{1}$ MSTU “STANKIN", department "Engineering Ecology and Life safety”, 127055 Moscow Vadkovsky lane, 3a, Russia
}

\begin{abstract}
The article examines the issues of creation of the best available technologies of formshaping and the methodology of quantitative evaluation of their effectiveness. It is shown that creation of a unified methodology for generation of best available technologies of form-shaping and quantitative evaluation of the effectiveness of these technologies is possible on the basis of energyrelated representation of technological processes. In this case, the technological process is represented as two processes - the process of converting electrical energy into mechanical energy and the process of transfer of mechanical energy to the processing zone. This approach allows to create unified methodologies regardless of the wide variety of technological processes of formshaping, conditions and parameters of their implementation. It is shown that for each particular implementation of technological processes of form-shaping, energy losses during conversion and transfer of energy and increased consumption of current due to "underload" of process equipment determine the environment friendliness of each specific implementation of the technological process. The main directions for improvement of efficiency of the best available technologies of form-shaping are indicated.
\end{abstract}

\section{Problem definition}

Technological processes of form-shaping are among the most important types of human economic activities; their implementation in a large measure determines the economic potential of any country, defines the competitiveness of products. For this reason, major attention is paid to improving the quality of these technological processes. This also applies to implementation of advanced technologies of formshaping and information technologies as well as to improvement of automation facilities, improvement of tools quality and other innovations [1-9].

The most important quality indices of technological processes are the indices that characterize their impact on the environment and on humans manifested through consumption and wastes (fig.1).

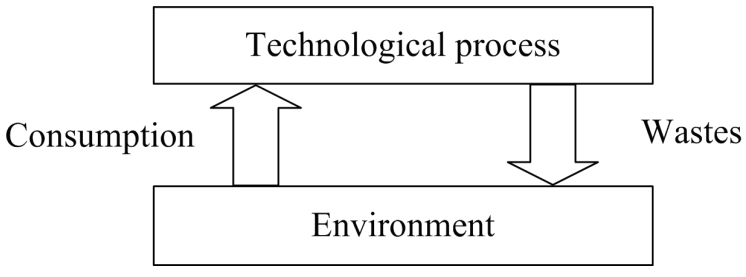

Fig. 1. Impact of technological processes on the environment and humans.

It should be noted that the products also are a waste, merely delayed in time. Therefore, environmentally invariant technological processes of form-shaping do not exist.

It should also be noted that technological processes of form-shaping are characterized by large diversity of types and kinds (milling, grinding, etc.), by technical characteristics of equipment on which they are implemented, by conditions of their implementation. Besides, their implementation requires extra-wide range of regulation, reaching values of 10,000:1 and higher, and ultra-small error.

For this reason, the problem of reducing the impact of form-shaping technological processes on the environment and humans in course of specific implementation of these processes is a major problem facing Russia's machine-building industry; solving this problem is aimed at improving the quality of these processes as well as at increasing their competitiveness.

\section{Analysis of recent achievements in the study area}

An important factor in reducing the impact of technological processes of form-shaping on the environment and humans is the creation of technologies of form-shaping as best available technologies (BAT).

BAT is a technology for manufacture of products (goods), performance of works, rendering of services determined on the basis of achievements of science and engineering and the best combination of criteria for

\footnotetext{
* Corresponding author: lesh@stankin.ru
} 
achieving the aims of environment protection, on condition of availability of technical feasibility of its application.

These criteria include:

- the lowest level of negative impact on the environment per unit of time or per volume of manufactured products;

- economic efficiency of its implementation and operation;

- application of resource-saving and energy-saving methods;

- duration of implementation;

- industrial implementation at 2 or more facilities.

Currently the regulatory framework in Russia in the field of BAT implementation includes Federal laws, resolutions and orders of the Government of the Russian Federation, orders of the Ministry of industry and trade, Ministry of natural resources and environment and Rosstandart issued during the period 2014-2016. Rosstandart is the Federal executive body authorized by the Government of the Russian Federation dated 23.12.2014, No. 1458 for attesting a technology as best available technology.

As noted at the International forum of technological development TECHNOPROM 2014, implementation of BAT in various branches of economic activity is comprehensive and includes three main components industrial policy, ecological policy and improvement of the system of state regulation based on BAT.

Form-shaping technologies do not relate to technologies that require urgent transfer to BAT, as opposed, for example, to power-generation technologies or minerals extraction technologies. However, widespread character of these technologies and concentration in industrialized regions predetermine the necessity for proactive steps towards their transition to BAT.

\section{Purpose and objectives of the work}

The purpose of this work is the creation of a unified methodology for generation of form-shaping BAT and quantitative evaluation of the effectiveness of these technologies for each specific implementation of technological processes, taking into account the state of technological equipment, tools and conditions for the implementation of these processes.

The objective of this work is the substantiation of the interrelation of the energy-related representation of technological processes of form-shaping with their negative impact on the environment and humans.

\section{Main part}

Creation of a unified methodology for generation of form-shaping BAT and quantitative evaluation of the effectiveness of these technologies across wide variety of technological processes and conditions of their implementation can be provided through the energyrelated representation of these processes [10].
In this case, the technological process of formshaping may be represented as two processes - the process of converting electrical energy into mechanical energy and the process of transfer of mechanical energy to the processing zone.

The first process is performed by electric motors (AC or DC motors), and the second process - by the kinematics of the technological equipment.

As any physical processes, the processes of energy conversion and transmission involve losses that are characterized by the losses $\left(\Delta P_{\text {conv }}\right.$ and $\left.\Delta P_{\text {trans }}\right)$ of active component of consumed power. These losses form the negative impact of technological processes on the environment and on humans [11].

Indeed, for the formation of negative impact on the environment and on humans, energy is needed electromagnetic energy (electromagnetic pollution), heat energy (heat wastes), mechanical energy (vibration wastes, solid wastes), etc. Therefore, the energy of the negative impact on the environment and on humans is determined by the power losses during the implementation of these technological processes, because the energy source is only the energy supplied to the technological equipment.

For this reason, the active component of power consumed from the source exceeds the cutting power calculated by the technologist and applied to the motor shaft, and this excess, which is caused by losses, determines the negative impact of technological processes of form-shaping on the environment and on humans.

It should also be noted that when induction motors are used in technological equipment as converters of electrical energy into mechanical energy, it is necessary to take measures for providing the maximum value of power factor $(\cos \varphi)$. Low value of this coefficient is explained by the fact that, in the vast majority of cases, the equipment is operating at underload, i.e. at conditions when the cutting power reduced to the motor shaft is substantially smaller than the rated capacity of the motor $\left(P_{n}\right)$. This leads to emergence of substantial reactive component of the consumed power, and hence to increase of the value of total consumed power, what generates additional negative load on the environment [12].

Thus, these two factors - energy losses and low power factor - determine the negative impact of technological processes of form-shaping on the environment and humans during their implementation, and also the excessive consumption of energy (physically this means that the technological process is implemented at excessive values of consumption current).

In addition it should be noted that reduction of consumption of energy determined by $S$ value has a considerable environmental impact in itself, because electricity production is one of the types of economic activities that have the greatest negative impact on the environment.

To achieve the goals of environmental protection, what is required for creation of the best available technologies, it is necessary to fulfill two conditions. 
Firstly, it is necessary to reduce losses of active power during implementation of the technological process of form-shaping, and secondly, to improve the power factor.

So, the generation of form-shaping BAT is resolved into minimizing the full power $(S)$ consumed during implementation of these technologies by reducing the cutting power $\left(P_{c u t}\right)$ applied to the motor shaft through efficiency of the machine $(\eta)$ and energy losses $\left(\Delta P_{\text {conv }}\right.$, $\left.\Delta P_{\text {trans }}\right)$, and by improving the power factor $(\cos \varphi)(1)$.

$$
S=\frac{\left(P_{\text {cut }} / \eta\right)+\Delta P_{\text {conv }}+\Delta P_{\text {trans }}}{\cos \varphi}
$$

To a considerable extent this corresponds to BAT for ensuring energy efficiency presented in the European Climate Change Programme.

Based on the stated above, the diagram of generation of form-shaping BAT may be represented as shown in fig. 2.

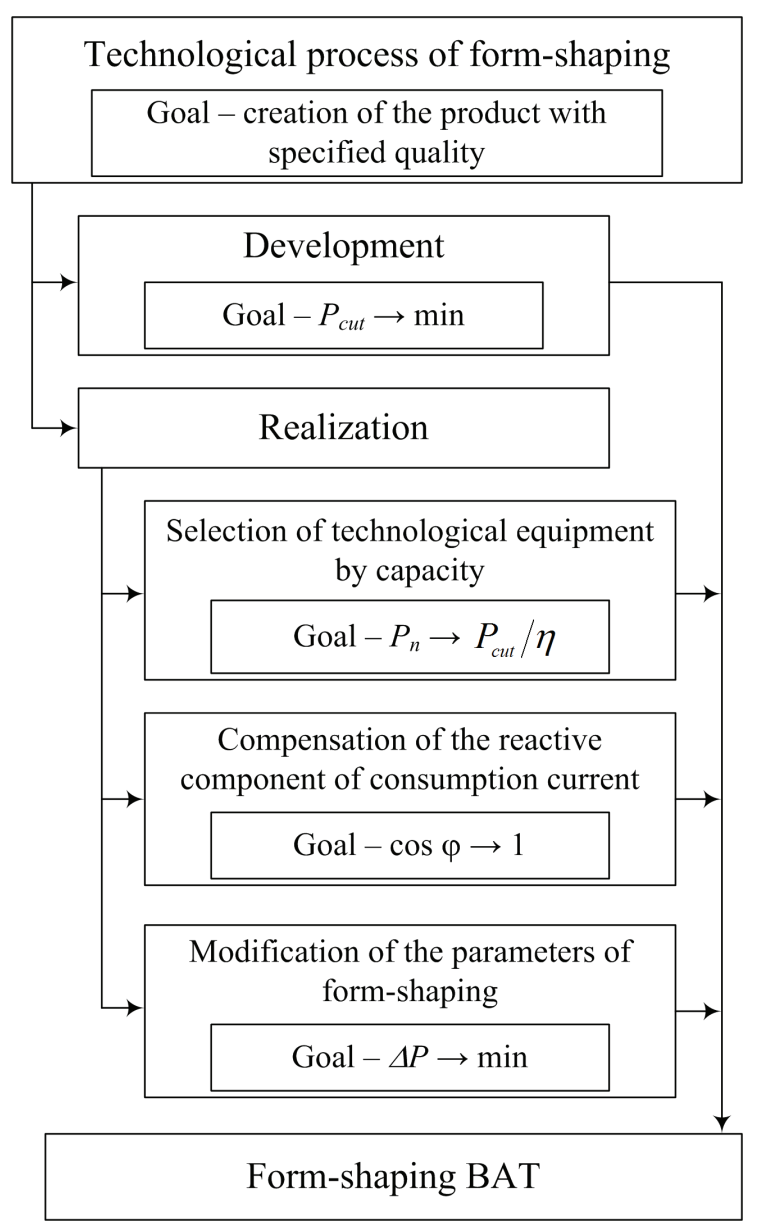

Fig. 3. Diagram of generation of form-shaping BAT.

All stated above applies equally to technological processes implemented on general-purpose equipment and $\mathrm{CNC}$ equipment, additive and digital technologies, nanotechnologies, to formation of lean production.

It should be added that after solving the technical issues of generation of form-shaping BAT, for inclusion of these technologies in BAT reference book it is necessary to carry out several organizational and organizationally-technical measures established by regulatory documents in this area of activities.

Hence, for generation of form-shaping BAT, the following set of measures should be recommended.

1. During development of the technological process, basing on state-of-the-art technologies, innovations, resource-saving and energy-saving, tool management and metrological support, in order to achieve BAT goal, the process engineer creates the technological process providing minimal cutting power of machining steps.

2. In course of implementation of technological processes of form-shaping, it is necessary to select the equipment by capacity of electric motors, achieving the value of cutting power reduced to the motor shaft as close as possible to motor rated power (to avoid «underload» of the machine as much as possible). Besides, operation of motor at idle should be minimized.

3. In case of « underload» of the machine during implementation of technological processes, it is necessary to install capacitors to compensate the reactive component of the consumption current, or install special energy-efficient motors in the technological equipment.

4. Reduction of energy losses during energy conversion and transmission to the processing zone is achieved by changing the parameters of the technological process of form-shaping. However, it may cause change of static and dynamic characteristics, stability of the system. All this may result in change of quality indices of the technological processes; if the quality indices decrease, the optimization problem must be solved.

Using this approach to creation of best available technologies of form-shaping, the quantitative evaluation of their effectiveness may be performed basing on the ratio of power required for cutting process and calculated by the technologist $\left(P_{c u t}\right)$, and consumed power measured $(S)$ for the specific implementation of the technological process of form-shaping. This ratio should be called the integrated environmental index of quality of technological processes I, because it takes into account the integral environmental impact of these processes due to energy losses $\left(\Delta P_{\text {conv }}\right.$ and $\left.\Delta P_{\text {trans }}\right)$ and machine « underload» ( $\cos \varphi$ is small) (2).

$$
I=\frac{P_{\text {cut }} / \eta}{S}=\frac{\left(P_{\text {cut }} / \eta\right) \cdot \cos \varphi}{\left(P_{\text {cut }} / \eta\right)+\Delta P_{\text {conv }}+\Delta P_{\text {trans }}}
$$

\section{Conclusions}

1. During generation of a form-shaping BAT, it is necessary to use energy analysis of technological processes, allowing the creation a unified methodology for the quantitative evaluation of the effectiveness of these technologies through comparison of cutting power with full consumed power.

2. Energy losses during implementation of technological processes and excessive consumption of current determine the aggregate effect of the specific implementation of the technological process on the environment and humans. 
3. This approach enables the quantitative assessment of effectiveness of general-purpose technologies as well as of digital and additive technologies, and facilitates the transition to lean machine-building production.

All of the above applies equally to the technological processes implemented on general-purpose equipment and $\mathrm{CNC}$ equipment, to additive and digital technologies, nanotechnologies, to formation of lean production.

Therefore, the introduction of best available technologies of form-shaping is one of the most important basic directions for increase of competitiveness of machine-building, because it is aimed at increasing of resource intensity, reducing of energy consumption of technological processes, at preventing adverse impacts on the environment and on humans, taking into account the particular features of the specific branch of industry.

\section{References}

1. S.B. Egorov, A.V. Kapitanov, V.G. Mitrofanov, L.E. Shvartsburg, N.A. Ivanova, S.A. Ryabov, Modern digital manufacturing technical support centers, Mathematics Education Open Access, 11, 7, 2213-2225 (2016)

2. A.V. Kapitanov, Special Characteristics of the Multi-product Manufacturing, Procedia Engineering 150, 832-836 (2016)

3. L. Shvartsburg, N. Ivanova, S. Ryabov, T. Zaborowski, Chemical contaminations in a process of polishing with an implementation of liquid LCTS, Life science journal 11(10s), 228-230 (2014)

4. L. E. Shvartsburg, E.V. Butrimova, N.V. Drozdova, Possibilities and adaptation of software product MS Visio for visualization of the ecological information, Practical and Educational-Methodical JOURNAL LIFE SAFETY 10, 35-37 (2011)

5. E.V. Butrimova, N.V. Drozdova, CALStechnologies in solving the problems of monitoring of energy pollutions, VESTNIK MSTU «STANKIN» 3, 43-45 (2008)

6. M. Yu. Khudoshina, O.V. Butrimova, Development methodology of information retrieval system for environmentally sound selection of lubricant cooling technological fluids in mechanical engineering, Technology of oil and gas 1, 54-59 (2014)

7. M. Yu. Khudoshina, O.V. Butrimova, Stage of conceptual design of the database of coolant-cutting technological means, systems for their application and disposal, VESTNIK MSTU «STANKIN» 1, 150-154 (2010)

8. S.N. Grigoriev, M.P. Kozochkin, F.S. Sabirov, A.A. Kutin, Diagnostic systems as basis for technological improvement, Procedia CIRP. 1, 599-604 (2012)

9. V.A. Grechishnikov, P.V. Domnin, V.A. Kosarev, Yu.E. Petukhov, V.B. Romanov, B.E. Sedov, Shaping by means of complex cutting tools, Russian Engineering Research 34 , 7, 461-465 (2014)
10. S.B. Egorov, A.V. Kapitanov, V.G. Mitrofanov, L.E. Shvartsburg, N.A. Ivanova, S.A. Ryabov, Formation of the integral ecological quality index of the technological processes in machine building based on their energy efficiency, International Journal of Environmental and Science Education 11, 11, 4065-4078 (2016)

11. L. E. Shvartsburg, E.V. Butrimova, N.V. Drozdova, Experimental research of distribution vibroacoustics factors in the environment for forecasting of their levels in the certain point of space, Practical and Educational-Methodical JOURNAL LIFE SAFETY 2, 27-30 (2012)

12. S. I. Gvozdkova, L. E. Shvartsburg, Minimization of energy losses by increasing the power factor, VESTNIK MSTU «STANKIN» 2, 32-36 (2012) 